\title{
The informative value and design of orthodontic practice websites in The Netherlands
}

\author{
Cesar Guy Oey and Christos Livas*
}

\begin{abstract}
Background: The aims of this cross-sectional study were to investigate the regulatory compliance of Dutch practice websites offering orthodontic services, readability of the available treatment information, website design as well as possible relationship with practice location and professional qualification of practitioners.

Methods: A comprehensive Internet search was performed using the Google search engine and five relevant terms in Dutch. Eligibility screening of the first 50 results of each search led to the final inclusion of 111 websites. The content of the selected websites was evaluated in terms of compliance to international regulations on ethical advertising guidelines (CED), treatment information text readability using Flesch Reading Ease Score (FRES), and website design using the BDC assessment tool.

Results: Reporting of websites according to CED guidelines covered on average $85 \%$ of the mandatory items. No significant differences were observed between dental and orthodontic practices, and between practices located in densely and sparsely populated regions $(P>0.05)$. The mean FRES of the displayed information indicated difficult-to-understand text. BDC scores of multi-location practices were significantly higher than the rest $(P<0.006)$.

Conclusions: The websites of orthodontic practices in The Netherlands do not fully comply with CED guidelines on ethical advertising. Readability of the displayed information and website technical performance needs to be further optimized.
\end{abstract}

Keywords: Websites, Practice management, Ethics, Patient education

\section{Background}

The practice website is nowadays considered an effective marketing and communication tool for a thriving orthodontic practice. Orthodontic practices with websites and active engagement through social media were positively related to new patient starts per year [1]. Online presence of the practice enables the spread of information to current and future patients regarding practice location, facilities, staff, and provided services while contacting the practice team is frequently initiated through the website [2].

\footnotetext{
* Correspondence: c.livas@acta.nl

Department of Orthodontics, Academic Centre for Dentistry Amsterdam (ACTA), University of Amsterdam and VU University Amsterdam, Gustav Mahlerlaan 3004, 1081 LA Amsterdam, The Netherlands
}

As the content of health-related websites has been criticized for extreme variability in quality, imbalance between posted information and patient health literacy, and likely interference of commercial interests, regulatory action has been taken at European Union (EU) and national level to optimize the development of dental practice websites [3]. The Council of European Dentists has published the Code of Ethics for Dentists (CED), a code including mandatory and discretionary provider and professional information that should be displayed on a dental website to guide commercial communications of dentists within EU and information services on the Internet [4]. In line with European guidance, the General Dental Council (GDC) in the UK has produced an ethical framework for regulating dental advertising by practice websites [5]. However, compliance of UK dental 
and orthodontic practices to GDC core principles is generally poor and rather slowly improving [2, 6-9].

To this end, the Royal Dutch Dental Association (KNMT: Koninklijke Nederlandse Maatschappij tot bevordering der Tandheelkunde), the professional association for dentists, oral surgeons, and orthodontists in The Netherlands, has recommended a 7-point checklist regarding the desired information available on practice websites [10]. Using a 60-item questionnaire developed by the authors, the content of Dutch dental practice websites was found to be highly variable. Strikingly, essential details like dentist's name, professional title, and registration number, e-mail address and last update date were often missing from the websites of Dutch dental practices [11].

Due to the widespread acceptance of orthodontics by the general Dutch population and shortage of practicing orthodontists, especially in non-metropolitan areas, 27$40 \%$ of the orthodontic caseload is being served by dentists [12, 13]. Given practice-specific parameters like location (i.e., urban vs. rural areas), ownership status (i.e., multi-owner vs. single-owner practice), and professional title (i.e., dentists vs. orthodontists) may have a certain impact on the website's quality [14], it would be interesting to investigate the informational content of the websites of the practices of orthodontic treatment providers in The Netherlands. Thus, the aims of this study were to examine the compliance of Dutch orthodontic practices to EU regulations (CED), readability of the posted orthodontic information, website design, and possible relationship of the aforementioned website features with practice location and professional qualification of practitioners.

\section{Methods}

\section{Search strategy}

Using Google (www.google.com), an Internet search was carried out on April 17, 2019. This decision was made on the basis of the high search validity and popularity of the Google search engine in The Netherlands $[15,16]$. Prior to initiating search, browser history, cookies, and cache were cleared. Five terms in Dutch were originally identified to yield the most Google results and subsequently used for the purposes of the study: "orthodontics," "orthodontic practice," "orthodontist's practice," "practice of orthodontists," and "dentist for orthodontics." Dutch professional associations have recently agreed upon using the title "dentist for orthodontics" by dentists practicing orthodontics to avoid confusion for patients. To outperform the standard online search behavior of a layperson limited to the first 8-10 results, the first 5 pages, were considered for eligibility [17-19]. Only websites of orthodontic practices, and dental practices providing orthodontic treatment located in the Netherlands were included.

\section{Website assessment Regulatory compliance}

Practice information was critically reviewed for compliance to CED by one observer (first author). The review focused on reporting mandatory information such as name and geographic address, contact details of the service provider, professional title and the country the title was obtained, license, and registration information. Websites were screened for optional CED items, namely opening and contact hours of the practice, details of emergency care, information about treatment techniques as well as links to professional associations like the Dutch Association of Orthodontists (NVvO; Nederlandse Vereniging van Orthodontisten) and the Orthodontic Association of General Practitioners (OVAP; Orthodontische Vereniging van Algemeen Practici).

\section{Readability of orthodontic information}

Text readability was evaluated by means of the Flesch Reading Ease Score (FRES) (Flesch 1948). FRES is an objective measurement of the reading level required by the reader to fully understand the text. The formula to calculate FRES is as follows: 206.835-(1.015 $\times$ Average number of words per sentence $)-(84.6 \times$ Average number of syllables per word). FRES ranges from 0 to 100, where a higher score indicates an easier-to-read text. Scores are categorized as follows: $0-29$ very confusing, 30-49 difficult, 50-59 fairly difficult, 60-69 standard, 70-79 fairly easy, $80-89$ easy, and $90-100$ very easy. A sample text of 200 to 500 words describing orthodontic appliances was extracted and tested using the Automatic Readability Checker, a free online text readability consensus calculator (http://www.readabilityformulas.com/ free-readability-formula-tests.php).

\section{Design}

To evaluate the form and function of websites, a free online website assessment tool (https://www.bdc.ca/en/articlestools/entrepreneur-toolkit/business-assessments/pages/freewebsite-evaluation.aspx), developed by bdc* (bdc*, Montreal, Quebec, Canada), was utilized. After entering the website URL, an overall score lying between 0 and 100 was generated, based on aspects including social media integration, web-optimized images, mobile speed, mobile optimization, search terms, and amount of content.

The collected data on CED reporting, FRES, and BDC scores were classified by provider's professional title (i.e., orthodontist, dentist or combination in case of multiple practitioners) and practice location (i.e., in the most three most densely populated provinces; North Holland, South Holland, and Utrecht, the rest of the provinces, and in more than one provinces). 


\section{Statistical analysis}

The presence of CED information was recorded in percentages, and differences between groups defined by practice location and professional qualification were assessed using chi-squared tests. For the numerical data, that is FRES and BDC scores, means, standard deviations, and ranges were calculated and differences between groups were tested using one-way analysis of variance (ANOVA). Statistical significance was set at 0.05 . All statistical analyses were conducted using IBM SPSS Statistics software version 25 (IBM Corp., Armonk, NY, USA).

\section{Results}

The search term combination yielded 4,024,900 results that were initially refined to 250 results. After applying the exclusion criteria for website type, a total of 111 websites were considered eligible (Fig. 1). Sixty-eight (62\%) of the websites belonged to orthodontic practices, and 28 (25\%) to dental practices offering orthodontic services.

\section{Reporting of mandatory CED information}

On average, the websites complied with 6.8 out of the 8 mandatory CED items. All websites regardless of classification revealed practice name, address, and phone number.
The lowest reporting rates were found overall for the provider's professional registration (41\%) and country of education in multi-location and multi-disciplinary practices $(20$ and $27 \%$, respectively) (Table 1 ). Websites of all practices established in multiple provinces reported 5 out of 8 mandatory CED items. No statistically significant differences were observed in reporting either between websites of orthodontic, dental and multi-disciplinary practices or websites of practices as classified by location $(P>0.05)$.

\section{Reporting of discretionary CED information}

Practice opening hours were listed by 102 out of 111 websites (92\%), followed by information regarding appliances and techniques (80\%), emergency contact details (64\%), and professional association links (57\%) (Table 2). Practices located in North Holland, South Holland, and Utrecht were significantly more likely to list emergency care information $(P=0.02)$, and orthodontists provided significantly more links to a professional association than the other providers $(P=0.0004)$.

\section{Readability}

The mean FRES of the examined information text (48.2) was categorized as difficult to read or requiring college

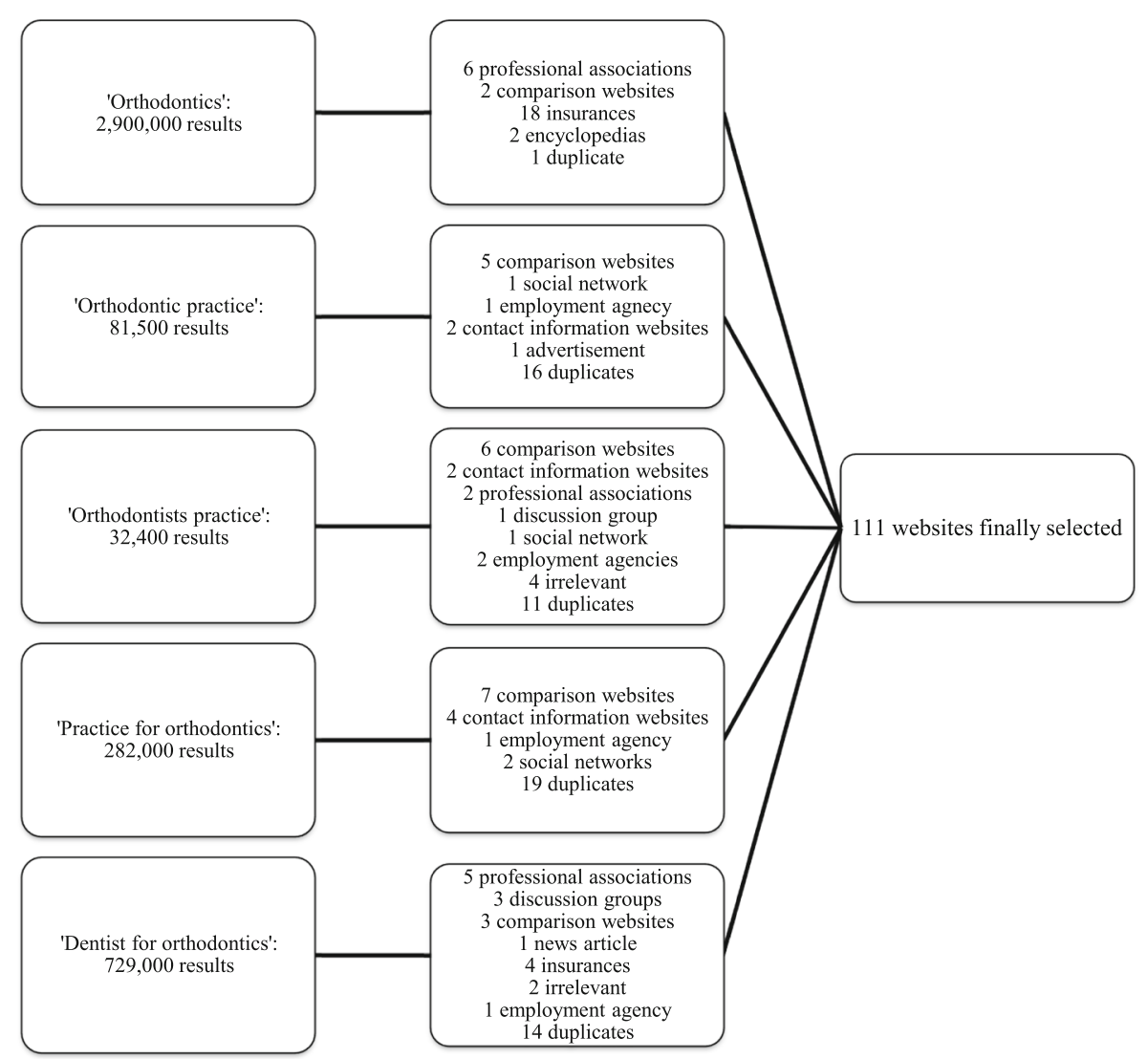

Fig. 1 Flowchart diagram of the selection process 
Table 1 Reporting of mandatory information items by the examined websites according to CED guidelines (in parentheses, the respective percentages)

\begin{tabular}{|c|c|c|c|c|c|c|c|}
\hline & & Professional ti & & & Practice loc & & \\
\hline & Overall & Orthodontist & Dentist & $\overline{\text { Combination }}$ & $\overline{\mathrm{NH}}, \mathrm{SH}, \mathrm{U}$ & Other provinces & Multiple provinces \\
\hline Provider's name & $103(93 \%)$ & $65(96 \%)$ & $27(96 \%)$ & $10(91 \%)$ & $51(98 \%)$ & $47(87 \%)$ & $5(100 \%)$ \\
\hline Practice address & $111(100 \%)$ & $68(100 \%)$ & $28(100 \%)$ & $11(100 \%)$ & $52(100 \%)$ & $54(100 \%)$ & $5(100 \%)$ \\
\hline E-mail & $102(92 \%)$ & 64 (94\%) & $26(93 \%)$ & 10 (91\%) & $50(96 \%)$ & $47(87 \%)$ & $5(100 \%)$ \\
\hline Phone number & $111(100 \%)$ & $68(100 \%)$ & $28(100 \%)$ & $11(100 \%)$ & $52(100 \%)$ & $54(100 \%)$ & $5(100 \%)$ \\
\hline Origin of education & 65 (59\%) & $54(79 \%)$ & $8(29 \%)$ & $3(27 \%)$ & $32(62 \%)$ & $32(60 \%)$ & $1(20 \%)$ \\
\hline Registration number & $45(41 \%)$ & $32(47 \%)$ & $9(32 \%)$ & $4(36 \%)$ & $21(52 \%)$ & $20(37 \%)$ & $4(80 \%)$ \\
\hline Practice name & 111 (100\%) & 68 (100\%) & $28(100 \%)$ & 11 (100\%) & $52(100 \%)$ & $54(100 \%)$ & $5(100 \%)$ \\
\hline
\end{tabular}

$\mathrm{NH}, \mathrm{SH}$, and $\mathrm{U}$ stand for the provinces of North Holland, South Holland, and Utrecht

level. FRES of orthodontic websites was significantly higher than that of dental websites $(P<0.01)$, but both fell under the same reading difficulty category (Fig. 2).

Readability scores of websites of practices located in the 3 most densely populated provinces were significantly higher than those located in multiple provinces $(P<0.035)$. Multilocation practices were assigned a mean FRES of 35.4, which refers to difficult-to-read text or college-level (Table 3).

\section{Design}

Two websites were not suitable for the application of the BDC tool and therefore excluded from the technical performance analysis. Websites of practices established in multiple provinces presented the highest mean BDC score (Table 3). BDC scores of these practices were significantly higher than those located in the 3 most densely populated provinces or other provinces $(P<0.006)$ (Fig. 3$)$.

\section{Discussion}

Ethical compliance of the websites of orthodontic and dental practices to the existing EU regulations has been so far indirectly investigated in the UK, using the GDC guidelines based on CED recommendations. These studies concluded that despite the progress made over time, UK orthodontic practice websites generally failed to comply with GDC instructions [2, 7-9]. In this sense, nearly 1 out of 10 orthodontic websites fully complied with the principles outlined by GDC [2].
According to the results of the present study, $26 \%$ of the examined Dutch websites were entirely compliant to CED mandatory items, with the provider's registration number being specified though, in less than half of the cases. Professional registration details were reported at higher rates ranging from 53 to $84 \%$ of orthodontic practices examined elsewhere $[2,8,9]$. On the contrary, such information was suboptimally provided by the UK and Dutch dental practice websites, viz., 19 and 27\%, respectively [6,11]. With respect to CED discretionary information, a link to a professional association was most frequently lacking but the websites outpaced previous reports [2, 7-9].

Furthermore, the mean FRES of the orthodontic information available on practice websites was difficult to read and required college-level reading skills. Research suggests that patient education materials should be written at a maximum reading level of sixth grade, which corresponds to a FRES of 80 , to be well understood by readers [20]. From this perspective, none of the websites achieved the recommended reading level.

The text on websites of orthodontists was significantly easier to comprehend compared to dentists and multidisciplinary practices, but the average reading level was still higher than the recommended level. However, orthodontic populations are globally, predominantly consisted of children and adolescents who should be accordingly instructed on-site and online [21]. Likewise, health information on $80 \%$ of Dutch websites regarding a wide range of medical conditions has been found to be

Table 2 Reporting of discretionary information items by the examined websites according to CED guidelines (in parentheses, the respective percentages)

\begin{tabular}{|c|c|c|c|c|c|c|c|}
\hline & \multirow[b]{2}{*}{ Overall } & \multicolumn{3}{|c|}{ Professional title } & \multicolumn{3}{|c|}{ Practice location } \\
\hline & & Orthodontist & Dentist & Combination & $\mathrm{NH}, \mathrm{SH}, \mathrm{U}$ & Other provinces & Multiple provinces \\
\hline Opening hours & $102(92 \%)$ & $61(90 \%)$ & $27(96 \%)$ & $11(100 \%)$ & 49 (94\%) & 48 (89\%) & $5(100 \%)$ \\
\hline Emergency care & $71(64 \%)$ & $42(62 \%)$ & $22(79 \%)$ & $11(100 \%)$ & $40(77 \%)$ & $29(54 \%)$ & $5(100 \%)$ \\
\hline Treatment information & 89 (80\%) & $57(84 \%)$ & $21(75 \%)$ & $9(82 \%)$ & 45 (87\%) & $40(74 \%)$ & $4(80 \%)$ \\
\hline Link to professional associations & $63(57 \%)$ & $51(75 \%)$ & $8(29 \%)$ & $4(36 \%)$ & $28(54 \%)$ & $34(63 \%)$ & $1(20 \%)$ \\
\hline
\end{tabular}

$\mathrm{NH}, \mathrm{SH}$, and $\mathrm{U}$ stand for the provinces of North Holland, South Holland, and Utrecht 


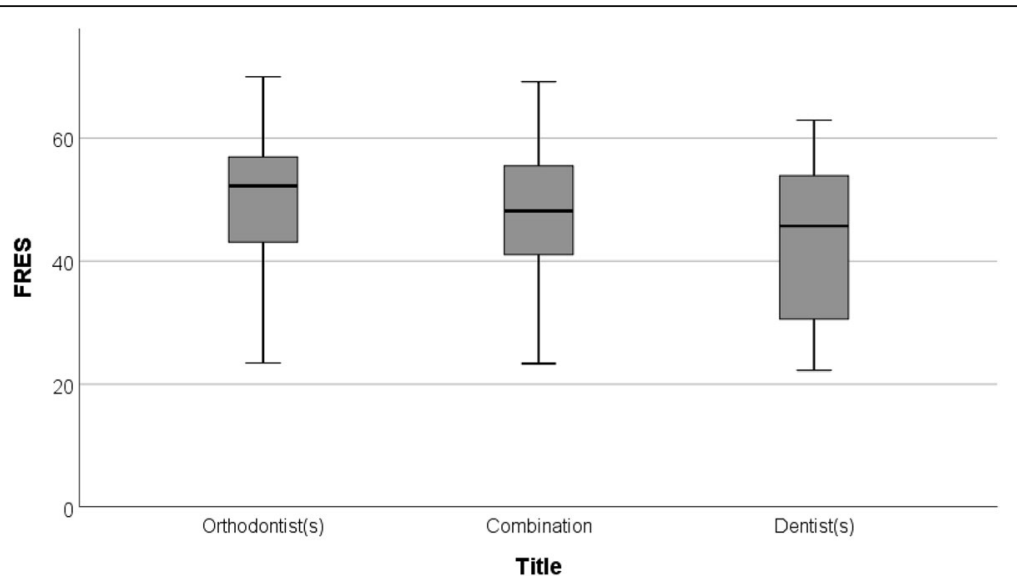

Fig. 2 Box-and-whisker diagram illustrating the distribution of FRES of website information as classified by provider's professional title

written on a reading level too difficult for individuals with low health literacy and deprived message elements that improve understanding of health materials [22]. Bearing in mind that $25 \%$ of the population in The Netherlands has inadequate health literacy, the potential implications of the readability results on processing online health information might be even more severe [23].

Hypothetically, high website quality might be expected by centrally located practices or the ones financially managed by multiple owners [14]. Websites of practices located in multiple provinces were assigned significantly higher BDC scores than the rest, indicating superior website optimization. Even though this type of practice was underrepresented in the study sample, it referred mostly to dental chains accounting for 148 practice locations across the country. Consolidation of dental care and the creation of groups of practices known as dental chains reflects a flourishing worldwide phenomenon in the healthcare industry [24]. In the USA, these large dental firms increased their establishments by 318\% within a decade [25]. In Europe, consolidation is mostly evident in Finland, where dental chains hold 35\% of the market in terms of the number of dentists. The ample resources of a dental chain and centralized back-office functions like shared IT service centers enable vertical integration of services such as advanced website design and support throughout the organization [24].

This study presents certain limitations that need to be acknowledged. Firstly, as in all cross-sectional observational studies, the sample of websites was collected at a single timepoint using a specific search strategy, and thus, interpretation of the findings should not be expanded. Nevertheless, the sample size can be considered relatively large and representative of the current orthodontic workforce in The Netherlands. Secondly, the content of the websites was evaluated in terms of adherence to ethical guidelines and readability, and not in terms of accuracy. As research on online orthodontic information has warned against the highly variable quality of materials related to treatment techniques, complications, and oral hygiene instructions, it would be useful to examine in the future the degree of agreement of the displayed text with the best available scientific evidence [26-30]. Thirdly, the evaluation of the technical design of the websites was performed by means of a rather new website assessment tool. Still, BDC is heavily used in business development strategies and provides an objective measure of the technical performance of a website.

The results of this multi-level website assessment advocate the need for the intensification of efforts to improve reporting of information in accordance with CED, simplify the context of the posted information, and optimize the technical design of the Dutch orthodontic practice websites. KNMT guidelines should be refined and monitored by domestic professional associations. Due to the dynamic nature of the Internet, regular review of the guidelines is necessary to keep pace with the constantly evolving technology [3]. In this direction, the

Table 3 FRES and BDC score means of website information and design, respectively (in parentheses, the standard deviations)

\begin{tabular}{|c|c|c|c|c|c|c|c|}
\hline & \multirow[b]{2}{*}{ Overall } & \multicolumn{3}{|c|}{ Professional title } & \multicolumn{3}{|c|}{ Practice location } \\
\hline & & Orthodontist & Dentist & $\overline{C o m b i n a t i o n}$ & $\mathrm{NH}, \mathrm{SH}, \mathrm{U}$ & Other provinces & Multiple provinces \\
\hline FRES & $48.2(11.5)$ & $50.6(10.1)$ & $43.0(12.0)$ & $46.8(14.1)$ & $49.1(11.8)$ & $48.9(10.8)$ & $35.4(8.3)$ \\
\hline BDC score & $53.9(12.3)$ & $52.4(11.3)$ & $55.8(13.7)$ & $60.8(13.0)$ & $54.8(12.8)$ & $51.5(11.0)$ & $69.2(9.7)$ \\
\hline
\end{tabular}

$\mathrm{NH}, \mathrm{SH}$, and $\mathrm{U}$ stand for the provinces of North Holland, South Holland, and Utrecht 


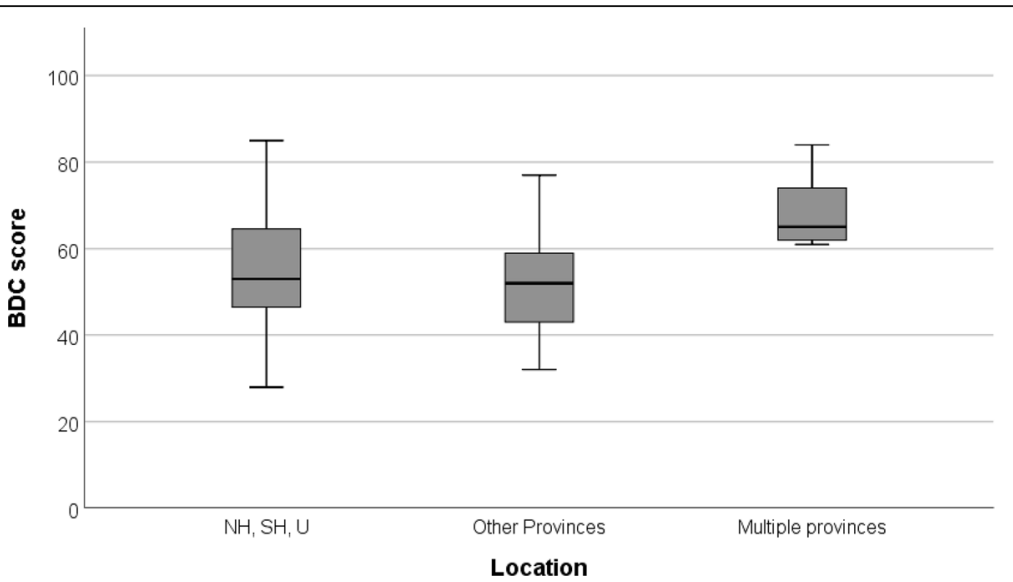

Fig. 3 Box-and-whisker diagram illustrating the distribution of BDC scores of the websites as classified by practice location. NH, SH, U stand for the provinces of North Holland, South Holland and Utrecht

close collaboration of EU with national health professional bodies may be helpful in facilitating transparent verification procedures like CE marking [31]. The informational content of the websites needs to be substantially revised to meet the reading standards of children and people with low health literacy. Inclusion of features that enhance information processing like animation, narration, and interactivity should be considered in developing appropriate orthodontic information materials [22]. Lastly, orthodontic practice websites may jointly cite easily understandable patient education materials approved by professional working groups and expert panels to ensure reading comprehension.

\section{Conclusions}

- Despite the websites of Dutch orthodontic care providers comply to a large extent to the mandatory CED items, basic professional information like registration number and origin of education is commonly missing.

- The available orthodontic information requires advanced reading skills and should be therefore properly revised.

- A significantly more advanced website design was observed in multi-location practices.

\section{Abbreviations}

CED: Code of Ethics for Dentists; EU: European Union; FRES: Flesch Reading Ease Score; GDC: General Dental Council; KNMT: Koninklijke Nederlandse Maatschappij tot bevordering der Tandheelkunde; NH: North Holland; NVvO: Nederlandse Vereniging van Orthodontisten; OVAP: Orthodontische Vereniging van Algemeen Practici; SH: South Holland; U: Utrecht; UK: United Kingdom

\section{Authors' contributions}

$\mathrm{CL}$ designed the study, collected, analysed and interpreted data, and drafted paper. CGO collected, analysed and interpreted data, and drafted paper. Both authors read and approved the final manuscript.

\section{Funding}

No funding

Availability of data and materials

The datasets used and/or analyzed during the current study are available from the corresponding author on reasonable request.

Ethics approval and consent to participate

Not applicable.

Consent for publication

Not applicable.

\section{Competing interests}

The authors declare that they have no competing interests.

Received: 29 September 2019 Accepted: 13 December 2019

Published online: 13 January 2020

\section{References}

1. Nelson KL, Shroff B, Best AM, Lindauer SJ. Orthodontic marketing through social media networks: The patient and practitioner's perspective. Angle Orthod. 2015:85:1035-41.

2. Patel A, Cobourne MT. The design and content of orthodontic practise websites in the UK is suboptimal and does not correlate with search ranking. Eur J Orthod. 2015:447-52.

3. Winker MA, Flanagin A, Chi-Lum B, et al. Guidelines for medical and health information sites on the internet: principles governing AMA web sites. JAMA 2000; 283:1600-6.

4. Manual of Dental Practice. Council of European Dentists. 2015. https:// cedentists.eu/library/eu-manual.html. Accessed 31st July 2019.

5. Guidance on advertising, 2013.General Dental Council. $2013 \mathrm{https}: / / w w w$. gdc-uk.org/professionals/standards/gdc-guidance. Accessed 31st July 2019.

6. Nichols LC, Hassall D. Quality and content of dental practice websites. Br Dent J. 2011;210:11.

7. Parekh J, Gill DS. The quality of orthodontic practice websites. Br Dent J. 2014;216:21.

8. Raimundo $H$, Robinson PK. An audit of implant practice websites: content and regulatory compliance. Br Dent J. 2014:217:673-7.

9. Budd ML, Davies M, Dewhurst R, Atkin PA. Compliance of NHS dental practice websites in Wales before and after the introduction of the GDC document 'Principles of ethical advertising'. Br Dent J. 2016;220:581-4.

10. Checklist Praktijkwebsite: Wegwijs in de praktijk. Koninklijke Nederlandse Maatschappij tot Bevordering der Tandheelkunde. https://www.knmt.nl/ sites/default/files/knmt_checklist_praktijkwebsite.pdf. Accessed 31st July 2019 
11. Poorterman JHG, Tjiook SP, Moeijes SFS, Brand HS. Websites van tandheelkundige praktijken langs de meetlat. Ned Tijdschr Tandheelkd. 2014;121:263-7.

12. Monitor mondzorg 2018. Nederlandse Zorgautoriteit. 2018. https://puc. overheid.nl/nza/doc/PUC_243564_22/1/. Accessed 30th July 2019.

13. Adriaanse B. Orthodontisch kwaliteitsregister voor tandartsen. Dental Tribune. 2014;February 12 Available at: https://nl.dental-tribune.com/news/ orthodontisch-kwaliteitsregister-voor-tandartsen/

14. Schwendicke F, Stange J, Stange C, Graetz C. German dentists' websites on periodontitis have low quality of information. BMC Med Inform Decis Making. 2017:17:114.

15. Wang $L$, Wang J, Wang $M, L i$ Y, Liang $Y, X u$ D. Using internet search engines to obtain medical information: a comparative study. J Med Internet Res. 2012;14:74.

16. Search Engine Market Share Netherlands, statcounter Globalstats. http://gs. statcounter.com/search-engine-market-share/all/netherlands. Accessed 30th July 2019.

17. Eysenbach G, Köhler C. How do consumers search for and appraise health information on the world wide web? qualitative study using focus groups, usability tests, and in-depth interviews. BMJ. 2002;324:573-7.

18. Delli K, Livas C, Vissink A, Spijkervet FK. Is YouTube useful as a source of information of Sjögren's syndrome? Oral Dis. 2016;22:196-201.

19. Livas C, Delli K, Pandis N. 'My Invisalign experience': Content, metrics and comment sentiment analysis of the most popular patient testimonials on YouTube. Prog Orthod. 2018;19:3.

20. Weis BD. Health literacy and Patient Safety: Help Patients Understand: Manual for clinicians. 2nd ed. Chicago, IL: AMA Foundation and AMA;2007:36

21. Keim RG, Gotlieb EL, Vogels DS, Vogels PB. 2014 JCO study of orthodontic diagnosis and treatment procedures, part 1: results and trends. J Clin Orthod. 2014;48:607-30.

22. Meppelink CS, van Weert JCM, Brosius A, Smit EG. Dutch health websites and their ability to inform people with low health literacy. Patient Educ Couns. 2017:100:2012-9.

23. Sørensen K, Pelikan JM, Röthlin F. Health literacy in Europe: comparative results of the European health literacy survey (HLS-EU). Eur J Public Health. 2015;25:1053-8.

24. Boogaard L, Maenpaa M, Preuß J, van der Schrier B. The dental chain opportunity: Consolidation of the European dental industry is in its early stages. KPMG International. 2017. Available at: https://assets.kpmg/content/ dam/kpmg/xx/pdf/2017/05/euro-dental-market.pdf. Accessed 30th July 2019

25. Wall T, Guay AH. Very Large Dental Practices Seeing Significant Growth in Market Share. Health Policy Institute, American Dental Association. 2015. http://www.ada.org/ /media/ADA/Science\%20and\%20Research/HPI/Files/ HPIBrief_0815_2.ashx. Accessed 30th July 2019

26. Patel U, Cobourne MT. Orthodontic extractions and the internet: quality of online information available to the public. Am J Orthod Dentofacial Orthop. 2011;139:103-9.

27. Doğramaci EJ, Rossi-Fedele G. The quality of information on the internet on orthodontic retainer wear: a cross-sectional study. J Orthod. 2016;43:47-58.

28. Olkun HK, Demirkaya AA. Evaluation of internet information about lingual orthodontics using DISCERN and JAMA tools. Turk J Orthod. 2018;31:50-4.

29. Livas C, Delli K, Ren Y. Quality evaluation of the available internet information regarding pain during orthodontic treatment. Angle Orthod. 2013:83:500-6.

30. Verhoef WA, Livas C, Delli K, Ren Y. Assessing the standards of online oral hygiene instructions for patients with fixed orthodontic appliances. J Am Dent Assoc. 2015;146:310-7.

31. Rigby M, Forsström J, Roberts R, Wyatt J. Verifying quality and safety in health informatics services. BMJ. 2001:323:552-6.

\section{Publisher's Note}

Springer Nature remains neutral with regard to jurisdictional claims in published maps and institutional affiliations.

\section{Submit your manuscript to a SpringerOpen ${ }^{\circ}$ journal and benefit from:}

- Convenient online submission

- Rigorous peer review

- Open access: articles freely available online

- High visibility within the field

- Retaining the copyright to your article

Submit your next manuscript at $\boldsymbol{\nabla}$ springeropen.com 